\title{
Hepatic PPARa is critical in the metabolic adaptation to sepsis
}

Citation for published version (APA):

Paumelle, R., Haas, J. T., Hennuyer, N., Bauge, E., Deleye, Y., Mesotten, D., Langouche, L., Vanhoutte, J., Cudejko, C., Wouters, K., Hannou, S. A., Legry, V., Lancel, S., Lalloyer, F., Polizzi, A., Smati, S., Gourdy, P., Vallez, E., Bouchaert, E., ... Staels, B. (2019). Hepatic PPARa is critical in the metabolic adaptation to sepsis. Journal of Hepatology, 70(5), 963-973. https://doi.org/10.1016/j.jhep.2018.12.037

Document status and date:

Published: 01/05/2019

DOI:

10.1016/j.jhep.2018.12.037

Document Version:

Publisher's PDF, also known as Version of record

\section{Document license:}

Taverne

\section{Please check the document version of this publication:}

- A submitted manuscript is the version of the article upon submission and before peer-review. There can be important differences between the submitted version and the official published version of record.

People interested in the research are advised to contact the author for the final version of the publication, or visit the DOI to the publisher's website.

- The final author version and the galley proof are versions of the publication after peer review.

- The final published version features the final layout of the paper including the volume, issue and page numbers.

Link to publication

\footnotetext{
General rights rights.

- You may freely distribute the URL identifying the publication in the public portal. please follow below link for the End User Agreement:

www.umlib.nl/taverne-license

Take down policy

If you believe that this document breaches copyright please contact us at:

repository@maastrichtuniversity.nl

providing details and we will investigate your claim.
}

Copyright and moral rights for the publications made accessible in the public portal are retained by the authors and/or other copyright owners and it is a condition of accessing publications that users recognise and abide by the legal requirements associated with these

- Users may download and print one copy of any publication from the public portal for the purpose of private study or research.

- You may not further distribute the material or use it for any profit-making activity or commercial gain

If the publication is distributed under the terms of Article $25 \mathrm{fa}$ of the Dutch Copyright Act, indicated by the "Taverne" license above, 


\section{Hepatic PPAR $\alpha$ is critical in the metabolic adaptation to sepsis}

\section{Graphical abstract}

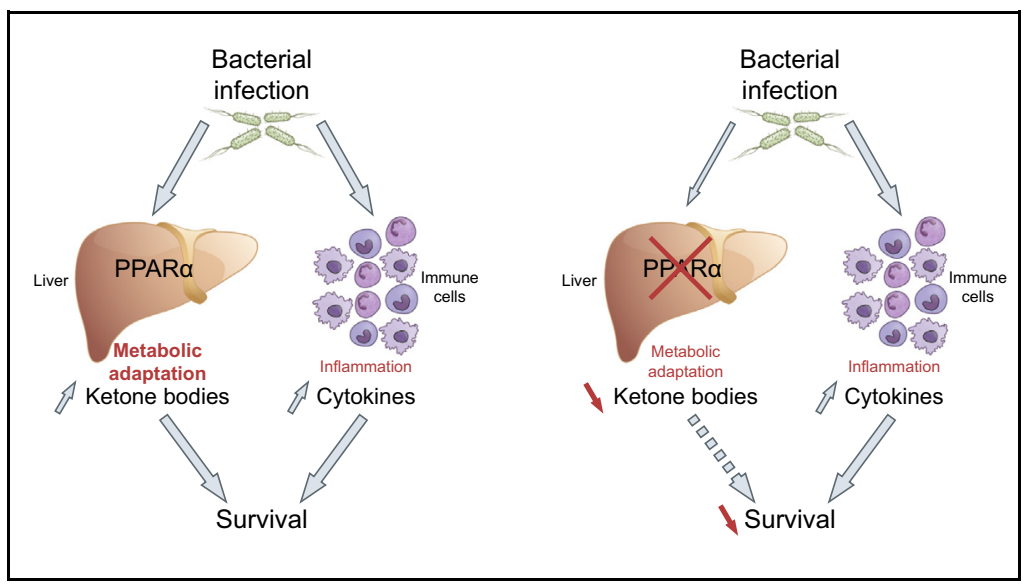

Highlights

- Sepsis activates hepatic PPAR $\alpha$.

- PPAR $\alpha$ plays a protective role in sepsis.

- Pparo-deficiency impairs FA utilization in the liver during sepsis.

- Hepatocyte Ppar $\alpha$-deficiency worsens the outcome of bacterial infection.

- PPAR $\alpha$ activity is lower in livers of non-surviving critically ill patients.

\section{Authors}

Réjane Paumelle, Joel T. Haas, Nathalie Hennuyer, ..., Hervé Guillou, David Dombrowicz, Bart Staels

\section{Correspondence}

bart.staels@pasteur-lille.fr

(B. Staels)

\section{Lay summary}

As the main cause of death in critically ill patients, sepsis remains a major health issue lacking efficacious therapies. While current clinical literature suggests an important role for inflammation, metabolic aspects of sepsis have mostly been overlooked. Here, we show that mice with an impaired metabolic response, due to deficiency of the nuclear receptor PPAR $\alpha$ in the liver, exhibit enhanced mortality upon bacterial infection despite a similar inflammatory response, suggesting that metabolic interventions may be a viable strategy for improving sepsis outcomes. 


\title{
Hepatic PPAR $\alpha$ is critical in the metabolic adaptation to sepsis
}

\author{
Réjane Paumelle $^{1, \dagger}$, Joel T. Haas ${ }^{1, \dagger}$, Nathalie Hennuyer ${ }^{1, \dagger}$, Eric Baugé ${ }^{1, \dagger}$, Yann Deleye ${ }^{1}$, \\ Dieter Mesotten $^{7}$, Lies Langouche ${ }^{7}$, Jonathan Vanhoutte ${ }^{1}$, Céline Cudejko ${ }^{1}$, Kristiaan Wouters ${ }^{2}$, \\ Sarah Anissa Hannou ${ }^{1}$, Vanessa Legry ${ }^{1}$, Steve Lancel $^{1}$, Fanny Lalloyer ${ }^{1}$, Arnaud Polizzi ${ }^{4}$, \\ Sarra Smati ${ }^{4}$, Pierre Gourdy ${ }^{3}$, Emmanuelle Vallez $^{1}$, Emmanuel Bouchaert ${ }^{1}$, Bruno Derudas ${ }^{1}$, \\ Hélène Dehondt ${ }^{1}$, Céline Gheeraert ${ }^{1}$, Sébastien Fleury ${ }^{1}$, Anne Tailleux ${ }^{1}$, Alexandra Montagner ${ }^{3,4}$, \\ Walter Wahli ${ }^{4,5,6}$, Greet Van Den Berghe ${ }^{7}$, Hervé Guillou ${ }^{4}$, David Dombrowicz ${ }^{1,+}$, Bart Staels ${ }^{1, *,+}$ \\ ${ }^{1}$ Univ. Lille, Inserm, CHU Lille, Institut Pasteur de Lille, U1011 - EGID, F-59000 Lille, France; ${ }^{2}$ Maastricht University, Dept. of Internal \\ Medicine, Maastricht, The Netherlands; ${ }^{3}$ Institut National de La Santé et de La Recherche Médicale (INSERM), UMR1048, Institute of Metabolic \\ and Cardiovascular Diseases, Toulouse, France; ${ }^{4}$ Institut National de La Recherche Agronomique (INRA), UMR1331 ToxAlim, Toulouse, \\ France; ${ }^{5}$ Lee Kong Chian School of Medicine, Nanyang Technological University Singapore, Clinical Sciences Building, 11 Mandalay Road, \\ Singapore 308232, Singapore; ${ }^{6}$ Center for Integrative Genomics, Université de Lausanne, Le Génopode, CH-1015 Lausanne, \\ Switzerland; ${ }^{7}$ Laboratory of Critical Care Medicine, Dept Cellular and Molecular Medicine, KU Leuven, University Hospitals Leuven, \\ Herestraat 49 Bus 503, B-3000 Leuven, Belgium
}

\begin{abstract}
Background \& Aims: Although the role of inflammation to combat infection is known, the contribution of metabolic changes in response to sepsis is poorly understood. Sepsis induces the release of lipid mediators, many of which activate nuclear receptors such as the peroxisome proliferatoractivated receptor (PPAR) $\alpha$, which controls both lipid metabolism and inflammation. We aimed to elucidate the previously unknown role of hepatic PPAR $\alpha$ in the response to sepsis.

Methods: Sepsis was induced by intraperitoneal injection of Escherichia coli in different models of cell-specific Pparadeficiency and their controls. The systemic and hepatic metabolic response was analyzed using biochemical, transcriptomic and functional assays. PPAR $\alpha$ expression was analyzed in livers from elective surgery and critically ill patients and correlated with hepatic gene expression and blood parameters.
\end{abstract}

Results: Both whole body and non-hematopoietic Pparadeficiency in mice decreased survival upon bacterial infection. Livers of septic Ppara-deficient mice displayed an impaired metabolic shift from glucose to lipid utilization resulting in more severe hypoglycemia, impaired induction of hyperketonemia and increased steatosis due to lower expression of genes involved in fatty acid catabolism and ketogenesis. Hepatocytespecific deletion of PPAR $\alpha$ impaired the metabolic response to sepsis and was sufficient to decrease survival upon bacterial infection. Hepatic PPARA expression was lower in critically ill patients and correlated positively with expression of lipid metabolism genes, but not with systemic inflammatory markers.

\footnotetext{
Keywords: Nuclear receptors; Sepsis; Metabolism; Hepatocytes; Inflammation. Received 13 February 2018; received in revised form 20 December 2018; accepted 23 December 2018; available online 21 January 2019

* Corresponding author. Address: Bart Staels. Inserm U1011, Institut Pasteur de Lille, 1 rue du Professeur Calmette, BP 245, Lille 59019, France. Tel.: +33 32087 73 88; fax: +33320877360.

E-mail address: bart.staels@pasteur-lille.fr (B. Staels).

$\dagger$ Co-first authors.

+ Co-senior authors.
}

Conclusion: During sepsis, Ppara-deficiency in hepatocytes is deleterious as it impairs the adaptive metabolic shift from glucose to FA utilization. Metabolic control by PPAR $\alpha$ in hepatocytes plays a key role in the host defense against infection. Lay summary: As the main cause of death in critically ill patients, sepsis remains a major health issue lacking efficacious therapies. While current clinical literature suggests an important role for inflammation, metabolic aspects of sepsis have mostly been overlooked. Here, we show that mice with an impaired metabolic response, due to deficiency of the nuclear receptor PPAR $\alpha$ in the liver, exhibit enhanced mortality upon bacterial infection despite a similar inflammatory response, suggesting that metabolic interventions may be a viable strategy for improving sepsis outcomes.

(C) 2019 European Association for the Study of the Liver. Published by Elsevier B.V. All rights reserved.

\section{Introduction}

Sepsis, the systemic inflammatory response to poorly controlled infection, causes significant morbidity/mortality. ${ }^{1}$ Sepsis is often complicated by multiple organ failure, requiring intensive care. Recently, mortality in sepsis has decreased largely due to improved supportive strategies for critically ill patients, such as mechanical ventilation, renal replacement therapy and antibiotics. While current therapeutic strategies targeting the inflammatory response have been disappointing, ${ }^{1,2}$ metabolic interventions, such as intensive insulin therapy ${ }^{3}$ and controlled caloric deficit through delayed administration of parenteral nutrition, ${ }^{4}$ have shown some promise, suggesting that appropriate adaptation of energy metabolism contributes to proper defense against pathogens. ${ }^{5}$

The early pro-inflammatory response to infection requires glycolysis and non-insulin-mediated glucose uptake to rapidly meet the high energy demand of innate immune cells. ${ }^{6}$ In this phase, hepatic gluconeogenesis increases to maintain plasma glucose concentrations. ${ }^{7}$ As sepsis sets in, plasma free fatty acid (FFA) and glycerol levels rise due to enhanced adipose tissue 
(AT) lipolysis. ${ }^{7}$ In response, organs such as the liver, muscle and heart, shift from glucose to fatty acid utilization ${ }^{8}$ and enhance mitochondrial activity. ${ }^{9}$

PPAR $\alpha$ is a nuclear receptor activated by fatty acids (FAs) and derivatives regulating both metabolism and inflammation. ${ }^{10}$ PPAR $\alpha$ is highly expressed in metabolic tissues, such as the liver, heart, kidney and muscle, the vasculature (endothelial cells, smooth muscle cells) as well as in the immune system (monocytes/macrophages, neutrophils, etc.). ${ }^{11}$ During the fed-tofasted transition, hepatic PPAR $\alpha$ expression increases ${ }^{12}$ and is activated by the influx of AT-released FFAs, orchestrating a shift from glucose to FA utilization driving ketone body and glucose production by the liver. ${ }^{12,13}$

PPAR $\alpha$ also exerts anti-inflammatory activities by inhibiting NFKB and AP1 signaling. ${ }^{10}$ Consequently, Ppara-deficient mice display a prolonged inflammatory response upon sterile inflammation. ${ }^{14}$ Conversely, upon polymicrobial infection, Pparadeficient mice display decreased survival associated with a reduced pro-inflammatory immune response, ${ }^{15}$ through mechanisms involving non-hematopoietic PPAR $\alpha .{ }^{16}$ Although cardiac PPAR $\alpha$ contributes to sepsis survival by increasing cardiac performance and FA oxidation, ${ }^{17}$ the specific contribution of PPAR $\alpha$ in the liver has not yet been addressed.

\section{Materials and methods \\ Mice}

Whole body Ppara knockout (KO) and wild-type (WT) littermate C57BL/6J mice (gift of F. Gonzalez ${ }^{18}$ ) were bred at the Institut Pasteur de Lille (IPL) transgenic rodent facility (SPF status). Hepatocyte-specific Ppara-deficient (Ppara fl/fl, Albumin-Cre ${ }^{+}$, Ppara $^{\text {hepKO}}$ ) and corresponding littermate controls (Ppara $\mathrm{fl} / \mathrm{fl}$, Albumin-Cre ${ }^{-}$) mice were generated and bred at INRA's rodent facility (conventional health status, Toxalim, Toulouse, France), as described. ${ }^{19}$ In survival experiments comparing Ppara ${ }^{\text {hepKO }}$ to whole body Ppara KO mice, all mice were bred at the INRA transgenic rodent facility. Infection experiments were conducted on female (8-12 weeks) mice fed a standard rodent diet (Safe 04 U8220G10R) at IPL facility. All animals were housed under temperature-controlled (at $22-24^{\circ} \mathrm{C}$ ), $12 \mathrm{~h}$ light/dark cycle conditions. Experimental procedures were approved by the Nord Pas-de-Calais Ethics committee (CEEA 75, APAFIS\#7738-2015121713177853 v9).

\section{Bacterial cultures and infection}

$\mathrm{DH} 5 \alpha$ Escherichia coli were grown in LB Broth at $37^{\circ} \mathrm{C}$ to an $\mathrm{OD}_{600}$ of 0.6 , equivalent to $4-5 \times 10^{8}$ live bacteria/ml, collected by centrifugation, washed once with sterile PBS, and resuspended in cold PBS at 4-7 $\times 10^{8}$ live bacteria/ml. Concentration and viability were confirmed by plaque assay colony counting. Mice (10-15 mice/group) were injected intraperitoneally (i.p.) with $4-7 \times 10^{8}$ live bacteria/mouse in $1 \mathrm{ml}$ PBS and survival rates were monitored every $6 \mathrm{~h}$ for a week. For biochemical characterization, mice were killed by cervical dislocation $16 \mathrm{~h}$ after infection and serum and livers collected.

\section{Human study}

Post-mortem liver biopsies were taken from patients in an intensive care unit $(n=46)$, who were enrolled in a randomized controlled trial. ${ }^{3}$ All deaths occurred after multidisciplinary decision to restrict therapy when further treatment was judged to be futile. During this trial, for post-mortem tissue sampling for academic purposes, each patient or his/her legal representative consented upon admission, via a hospital-wide information and consent procedure that required active opting-out when not consenting. Opting-out remained possible until time of death. This strategy was approved by the Institutional Ethical Review Board. Liver samples were harvested within minutes after death. Control liver biopsies from 20 demographically matched patients (written informed consent obtained prior to the procedure) undergoing an elective restorative rectal resection were obtained. All protocol and consent forms were approved by the Institutional Ethical Review Board of the KU Leuven (ML1094, ML2707). Baseline and outcome variables are indicated in Table S1. Liver biopsies were taken from liver segment IVb, snap-frozen in liquid nitrogen, and stored at $-80^{\circ} \mathrm{C}$ until analysis (see supplementary information).

\section{Biochemical analysis}

Plasma aspartate aminotransferase (AST) and alanine aminotransferase (ALT) (Biolabo), FFA (Diasys), $\beta$-hydroxybutyrate (ketone bodies) (Thermo Fisher) were determined by colorimetic assays. Plasma TNF $\alpha, \mathrm{Kc} / \mathrm{Cxcl} 1$ and IL-6 protein levels were measured by ELISA (R\&D Systems) and myeloperoxidase (MPO) activity as described. ${ }^{20}$ Cytokine levels were quantified in serum of critically ill patients collected on the day of biopsy (last day alive in the intensive care unit). ${ }^{21}$

\section{Liver transcriptomic analysis}

RNA extraction and analysis are detailed in the supplementary information. RNA microarray analysis was performed using Mouse Gene 2.0ST arrays. Array data processing was performed using Bioconductor in the R-environment (r-project.org). Gene expression was calculated after normalizing signal using robust multichip averaging in the oligo package. ${ }^{22}$ Differential gene expression between groups (Ppara WT uninfected, Ppara WT infected, Ppara KO uninfected and Ppara KO infected) was assessed using the limma package ${ }^{23}$ with a threshold of $5 \%$ false discovery rate. Differentially expressed genes were clustered using the hopach package ${ }^{24}$ with the cosine distance metric. Gene Ontology (GO) term enrichment of selected clusters was performed using the clusterProfiler package. ${ }^{25,26}$ For KEGG pathway analysis, data were analyzed using Partek software.

\section{Mitochondrial respiration}

Liver samples (125 mg) were minced and dounce homogenized by $8-10$ strokes in ice-cold MIR05 respiratory buffer $(20 \mathrm{mM}$

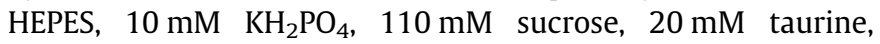
$60 \mathrm{mM}$ K-lactobionate, $0.5 \mathrm{mM}$ EGTA, $3 \mathrm{mM} \mathrm{MgCl} 2 \cdot 6 \mathrm{H}_{2} \mathrm{O}, 1 \mathrm{~g} / \mathrm{L}$ BSA (fatty acid free)). Liver homogenates $(50 \mu \mathrm{l})$ were introduced into $\mathrm{O} 2 \mathrm{~K}$ oxygraph chambers (Oroboros Instruments, Innsbruck, Austria) to assess oxygen consumption in presence of pyruvate $(5 \mathrm{mM})$ and malate $(2 \mathrm{mM})$ (state 2 respiration), followed by ADP $(0.5 \mathrm{mM})$ (state 3 respiration). To measure $\beta$ oxidation, octanoylcarnitine $(25 \mu \mathrm{M})$ and malate $(2 \mathrm{mM})$ were added, followed by ADP $(0.5 \mathrm{mM})$. The respiratory control ratio was calculated as the state 3:state 2 ratio. Finally, cytochrome c $(10 \mu \mathrm{M})$ was added to measure mitochondrial integrity.

\section{Histological analysis}

Frozen liver samples were embedded in Frozen Section Medium (NEG-50, Richard-Allan Scientific), stained with anti-Moma2 (ab33451, abcam) or anti-Ly6G (1 A8, BD Pharmingen) antibodies and counterstained with hematoxylin. Ly6G and Moma2 
staining areas were determined by color detection using a Nikon Eclipse Ti microscope and a color video camera coupled to the NIS Elements software (Nikon).

\section{Statistical analysis}

Groups were compared using the Log-rank (Mantel-Cox) Test (survival test), 2-way ANOVA, 2-tailed non-paired $t$ tests or nonparametric Wilcoxon tests (mouse and human studies) and expressed as means \pm SEM using the GraphPad Prism software. Significance of correlations between parameters was assessed by calculation of the Pearson ( $r$ ) correlation coefficient using GraphPad Prism software.

For further details regarding the materials and methods used, please refer to the CTAT table and supplementary information.

\section{Results}

Whole body and non-hematopoietic Ppara-deficiency aggravate mortality upon bacterial infection

To evaluate the role of PPAR $\alpha$ in sepsis, whole body Pparadeficient (KO) and WT mice were inoculated with Gramnegative Escherichia coli. Three days after infection, mortality was $0 \%$ in Ppara WT compared to $75 \%$ in Ppara KO mice (Fig. 1A). As PPAR $\alpha$ is expressed in immune cells and exerts anti-inflammatory actions, we assessed whether restoration of PPAR $\alpha$ in the hematopoietic compartment conferred protection to infection. Chimeric mice were generated by transplanting lethally irradiated whole body Ppara KO and Ppara WT mice with Ppara WT bone marrow (WTbm->KO and WTbm->WT, respectively, see supplementary information). Surprisingly, Ppara-deficiency in non-hematopoietic cells was still associated with increased mortality in response to infection (20\% Ppara WTbm->WT compared to 70\% Ppara WTbm->KO mortality 3 days after infection; Fig. S1A), revealing a protective role for non-hematopoietic PPAR $\alpha$ in response to sepsis.

Whole body Ppara-deficiency results in impaired metabolic and inflammatory responses to bacterial sepsis

To understand the mechanisms of increased mortality of Ppara KO mice in response to sepsis, the systemic metabolic and inflammatory response to bacterial infection was characterized. Plasma FFA levels significantly increased during sepsis to a similar extent in Ppara WT and KO mice at $16 \mathrm{~h}$ after infection (Fig. 1B), when maximal changes in metabolic parameters are observed (Fig. S2). Plasma AST and ALT levels were similar in Ppara WT and KO mice, suggesting comparable tissue damage (Fig. 1C,D). Conversely, plasma ketone body levels increased strongly upon infection in WT, but not in Ppara KO mice (Fig. 1E). In addition, infection-induced hypoglycemia was more
A
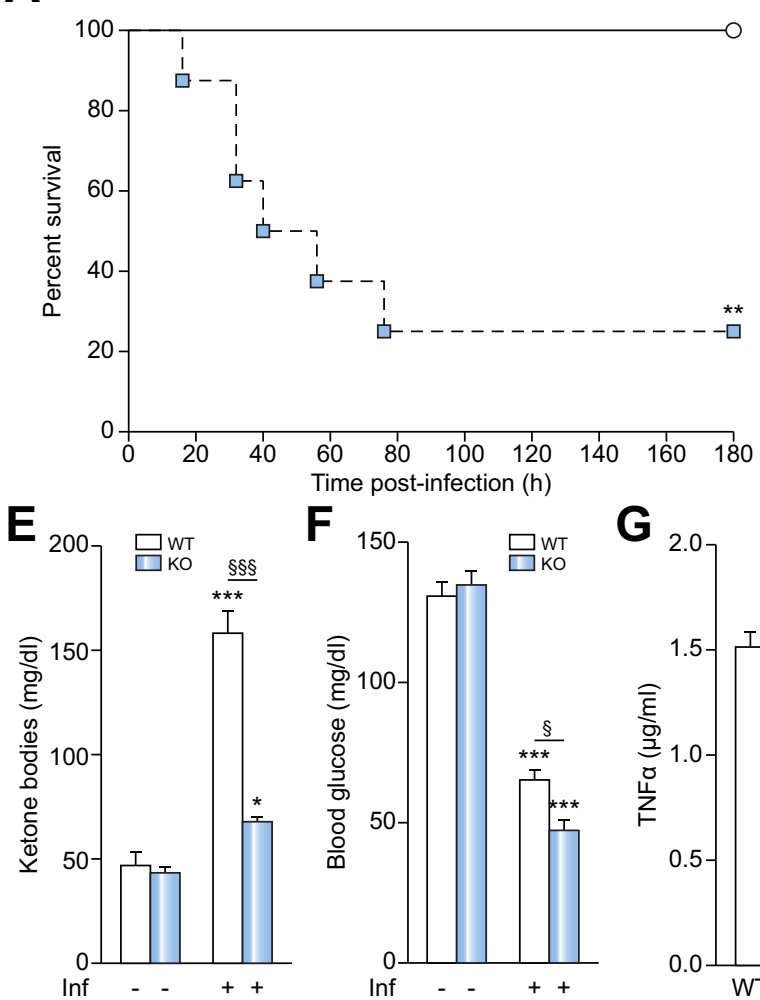

$\mathbf{F}$

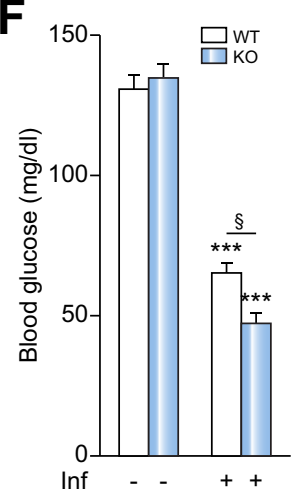

B

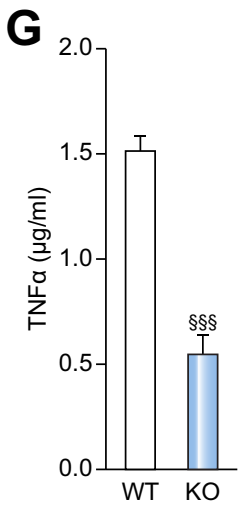

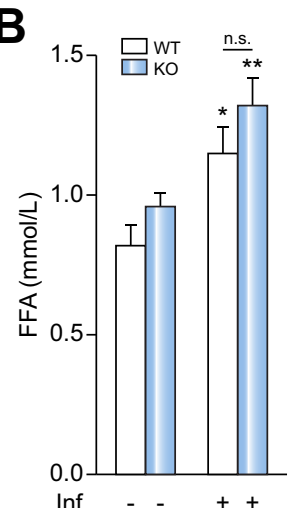
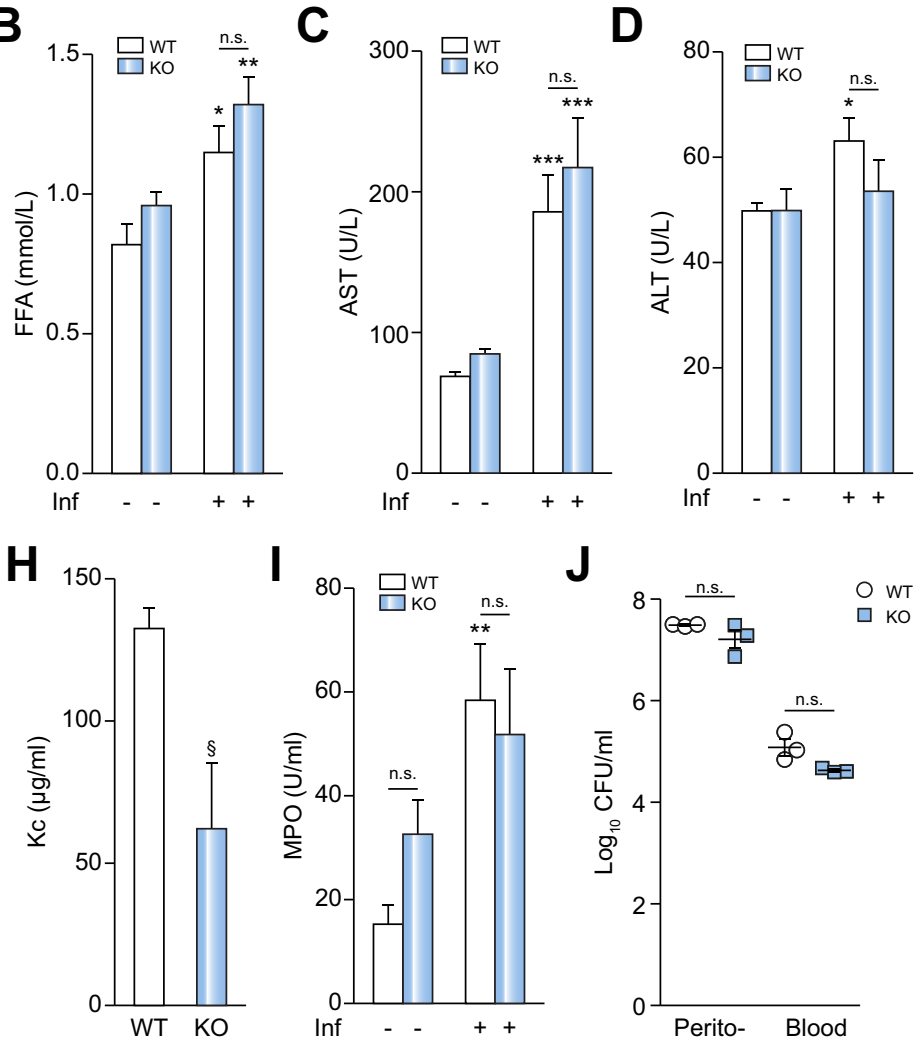

$J$

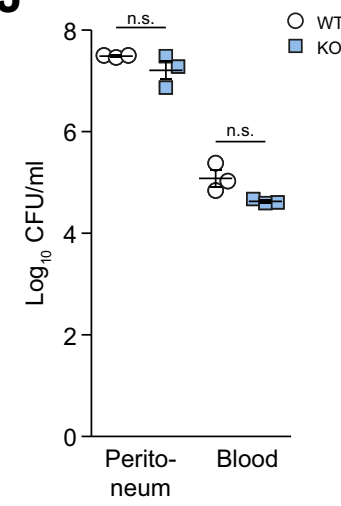

Fig. 1. Whole body Ppara-deficiency enhances mortality upon bacterial sepsis and impairs the metabolic and inflammatory response to bacterial infection. Ppara WT and KO mice were injected (ip) with vehicle (PBS) (-) or E. coli $\left(4 \times 10^{8}\right.$ live bacteria) (Inf) (+). (A) Survival was followed for 8 days after injection ( $\mathrm{n}=8-10$ mice/group). Plasma was collected (G,H) 6 h or (B-F, I-J) 16 h after injection and (B) FFAs, (C) AST, (D) ALT, (E) ketone bodies, (F) blood glucose, $(\mathrm{G}) \mathrm{TNF} \alpha,(\mathrm{H}) \mathrm{Kc} / \mathrm{Cxcl} 1$ concentrations and (I) MPO activity were measured as described in methods. (J) Bacterial levels in peritoneal fluid and blood were measured by retro-culture $\left(\mathrm{n}=3\right.$ mice/group). Statistical differences are indicated (Survival test: Log-rank (Mantel-Cox) Test: ${ }^{* *} p<0.01$. 2 -way ANOVA: ${ }^{* * *} p<0.001,{ }^{* *} p<0.01$ and ${ }^{*} p<0.05$ for effect of infection; $\$ \S p<0.001$; $\$ \S p<0.01$; $\S_{p}<0.05$ for genotype effect; n.s.: non-significant). ALT, alanine aminotransferase; AST, aspartate aminotransferase; FFAs, free fatty acids; KO, knockout; MPO, myeloperoxidase; WT, wild-type. 
pronounced in Ppara KO mice, suggesting defective glucose homeostasis (Fig. 1F). Interestingly, infected chimeric Ppara WTbm->KO mice also displayed lower plasma ketone body levels and more pronounced hypoglycemia compared to WTbm->WT controls (Fig. S1B,C). These results demonstrate that the metabolic response to sepsis depends on PPAR $\alpha$ expression in non-hematopoietic derived cells. In line with previous observations, ${ }^{15}$ Ppara-deficiency resulted in decreased, rather than increased, inflammatory responses as illustrated by lower plasma tumor necrosis factor alpha (TNF $\alpha$ ) and chemokine $\mathrm{Kc} /$ Cxcl1 levels $6 \mathrm{~h}$ after infection (Fig. 1G,H). Since hepatic PPAR $\alpha$ contributes to systemic inflammation, ${ }^{27}$ histological analysis of livers from infected Ppara WT and KO mice was performed. Surprisingly, whole body Ppara-deficiency did not affect infectioninduced neutrophil or monocyte/macrophage recruitment in livers as assessed by Ly6G and Moma2 stainings (Fig. S3). Plasma MPO activity (Fig. 1I) and bacterial dissemination into peritoneum and blood (Fig. 1J) were also unaffected by whole body Ppara-deficiency.

\section{Whole body Ppara-deficiency modulates the hepatic metabolic and inflammatory gene expression responses to bacterial sepsis}

To identify molecular pathways regulated by PPAR $\alpha$ in response to sepsis, microarray analysis was performed on livers from whole body Ppara WT and KO mice $16 \mathrm{~h}$ after infection and from uninfected controls. In addition to inflammation-related pathways, the GO term "Oxidation-Reduction Process," was altered by infection in Ppara WT mice, suggesting altered mitochondrial function (Fig. 2A). Unbiased clustering analysis of genes affected by sepsis in either whole body Ppara WT or KO mice revealed 3 gene clusters (Fig. 2B,C and Fig. S4). While cluster 1 (black) and cluster 3 (purple) contained genes whose response to infection (induced or suppressed, respectively) was largely maintained in whole body Ppara KO mice, genes in cluster 2 (green) were either unresponsive or responded in the opposite direction in Ppara KO mice despite strong regulation in Ppara WT mice upon infection. Cluster 1 was enriched in genes associated with inflammatory response and reactive oxygen species metabolism, and cluster 3 was enriched in genes involved in cellular glucuronidation and response to xenobiotics (Fig. S4). Interestingly, Cluster 2 contained many genes related to FA metabolism and circadian rhythm, many of which are bona fide PPAR $\alpha$ targets. Indeed, carnitine palmitoyl transferase $(C p t) 1 a$, acylCoenzyme A oxidase (Acox) 1 and pyruvate dehydrogenase kinase $(P d k) 4$, were induced by sepsis in Ppara WT mice, but either reduced or unchanged by infection in Ppara KO mice (Fig. 2D). Together, these results demonstrate that the most profound transcriptional differences between whole body Ppara WT and KO mice in response to sepsis are related to regulation of PPAR $\alpha$ 's metabolic targets, rather than to effects on inflammation or other pathways.

Whole body Ppara-deficiency impairs the hepatic metabolic shift from glucose to lipid utilization during bacterial sepsis To further characterize the metabolic role of PPAR $\alpha$ during sepsis, glucose and lipid metabolism gene expression was measured in livers of infected Ppara WT and KO mice (Fig. S5). Sepsis increased expression of genes involved in gluconeogenesis, such as phosphoenolpyruvate carboxykinase (Pck)1 and fructose-1,6-biphosphatase $(F b p) 1$, although the magnitude of response was lower in Ppara KO mice (Ppara WT vs. KO: Pck1:
3.00 vs. 1.67; Fbp1: 2.81 vs. 1.44-fold induction) (Fig. S5A). However, sepsis raised expression of Pdk4, which inhibits the final step of glycolysis, $>100$-fold in a PPAR $\alpha$-dependent manner (Fig. S5B). Similarly, sepsis strongly increased ( $>12$-fold) hepatic adipose triglyceride lipase (Atgl/Pnpla2) expression in Ppara WT mice only (Fig. S5C). Moreover, sepsis increased several PPAR $\alpha$ target genes involved in hepatic lipid metabolism such as FA uptake (e.g. Fatp1, Cd36), FA activation (e.g. Acsl1), peroxisomal FA $\beta$-oxidation (Acox1) and mitochondrial FA transport and $\beta$ oxidation (e.g. Cpt1a, Lcad) (Fig. S5D). Interestingly, except for Cpt1a, sepsis-mediated induction of these genes was PPAR $\alpha$ dependent. Moreover, expression of 3-hydroxy-3-methylglu taryl-Coenzyme A synthase (Hmgcs)2, the rate-limiting enzyme for $\beta$-hydroxybutyrate production, was lower in Ppara-deficient mice (Fig. S5E). Furthermore, infected chimeric Ppara WTbm$>$ KO mice, expressing Ppara only in hematopoietic cells, also displayed lower hepatic expression of Pdk4, Cd36, Acox1, Lcad, Hmgcs2 and Atgl compared to WTbm->WT mice (Fig. S5F,G), demonstrating that the metabolic transcriptional response to sepsis in the liver depends on non-hematopoietic PPAR $\alpha$.

Functional analysis of liver mitochondria also suggested impaired FA utilization in whole body Ppara KO mice. Unaltered citrate synthase activity indicated that Ppara-deficiency did not impact mitochondrial quantity (Fig. S5H). Uninfected whole body Ppara KO livers displayed lower respiratory control ratio values upon incubation with pyruvate and malate and, to a lesser extent, with octanoylcarnitine and malate compared to uninfected Ppara WT (Fig. 2E). However, bacterial infection shifted the respiration rate from pyruvate/malate to octanoylcarnitine/malate in Ppara WT, whereas this shift was less apparent in Ppara KO livers (Fig. 2E). Together, these data indicate that sepsis shifts the transcriptional and metabolic program from glucose to lipid utilization and this is impaired in whole body Ppara KO livers.

\section{Hepatocyte-specific PPAR $\alpha$ expression is required for proper metabolic response and survival upon bacterial infection}

Because the results of both transcriptomic and metabolic analysis suggested that hepatic PPAR $\alpha$ is activated upon sepsis, we postulated that hepatic PPAR $\alpha$ may be critical to the organism's response to infection. Therefore, hepatocyte-specific Ppara ${ }^{\text {hepKO }}$ were subjected to bacterial infection and their response compared to Ppara hepWT and whole body Ppara KO mice. Similar to whole body Ppara KO mice, Ppara ${ }^{\text {hepKO }}$ showed increased mortality compared to Ppara ${ }^{\text {hepWT }}$ mice (Figs. $1 \mathrm{~A}$ and $3 \mathrm{~A}$ ). Infected Ppara $^{\text {hepKO }}$ mice also displayed lower ketone body levels compared to Ppara ${ }^{\text {hepWT }}$, despite similar levels of plasma FFA, ALT and AST (Fig. 3B-D and Fig. S6). Liver triglyceride (TG) content increased more markedly upon bacterial infection in Ppara hepKO vs. Ppara ${ }^{\text {hepWT }}$ mice (3.1 vs. 2.2-fold, Fig. 3F), suggesting defective hepatic lipid utilization. Surprisingly, infected Ppara ${ }^{\text {hepKO }}$ mice displayed no significant differences in glycemia (Fig. 3E), nor plasma levels of inflammatory cytokines (TNF- $\alpha, K c$ and IL-6) at both $5 \mathrm{~h}$ and $16 \mathrm{~h}$ after infection (Fig. 3G,H and Fig. S7) compared to Ppara ${ }^{\text {hepWT }}$. In addition, bacterial dissemination in peritoneum and blood did not differ between PparahepWT and Ppara $^{\text {hepKO }}$ mice (Fig. 3I). These data suggest that the increased mortality observed in whole body Ppara KO is unlikely caused by the different glycemic and systemic inflammatory responses.

Similar to whole body Ppara KO mice, PparahepKO mice displayed major defects in sepsis-modulated regulation of several genes involved in hepatic glucose (i.e. Pdk4, Fig. 4A) and lipid 


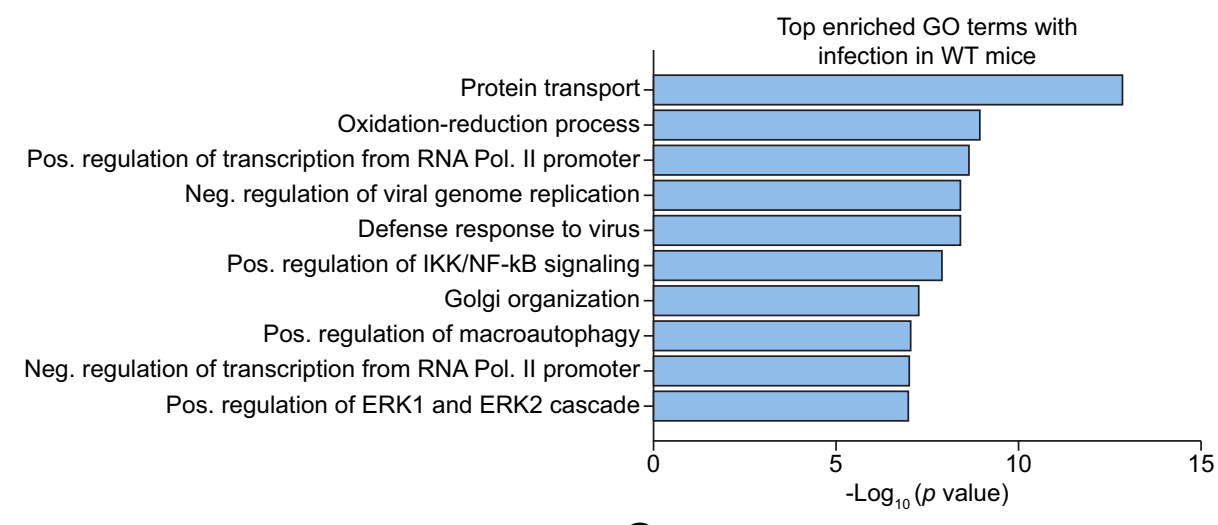

B

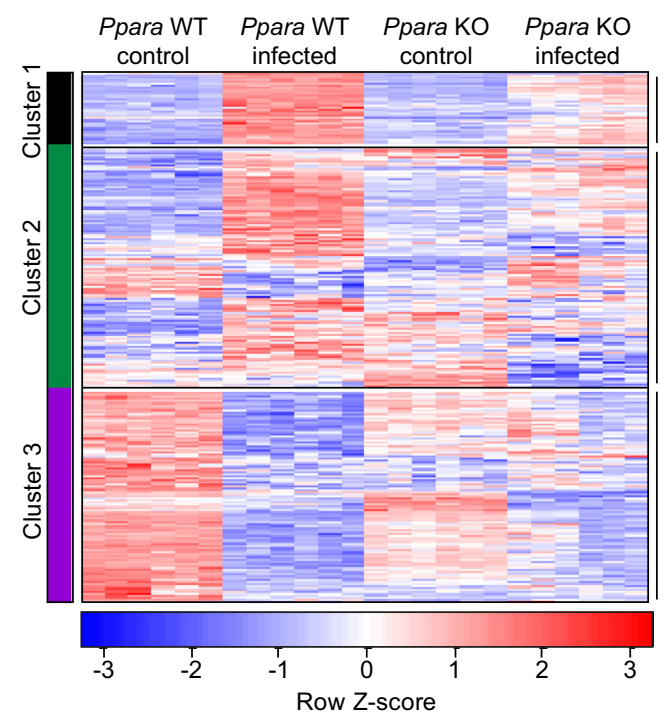

D

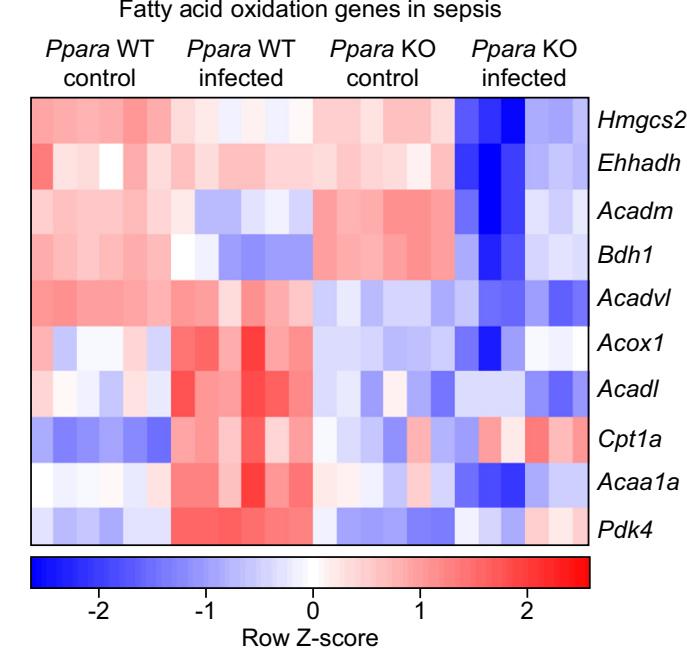

C

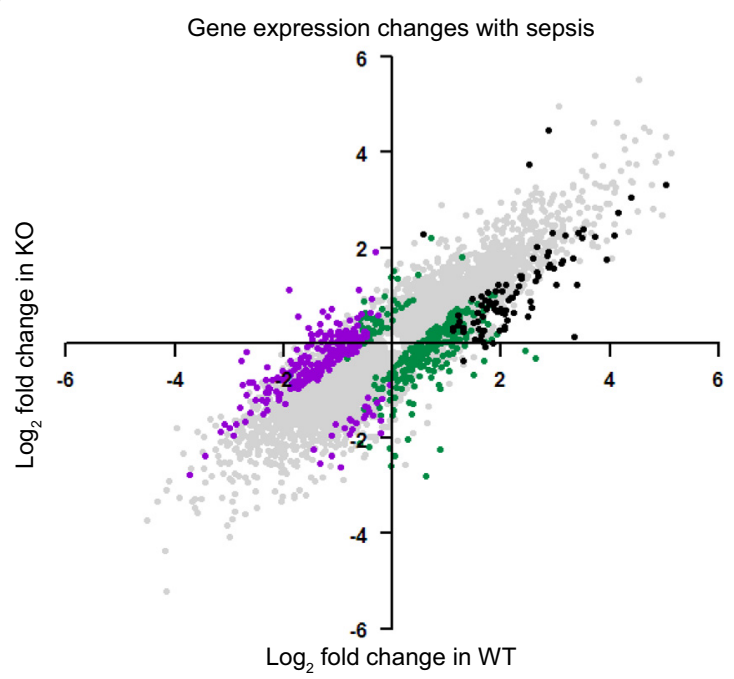

E

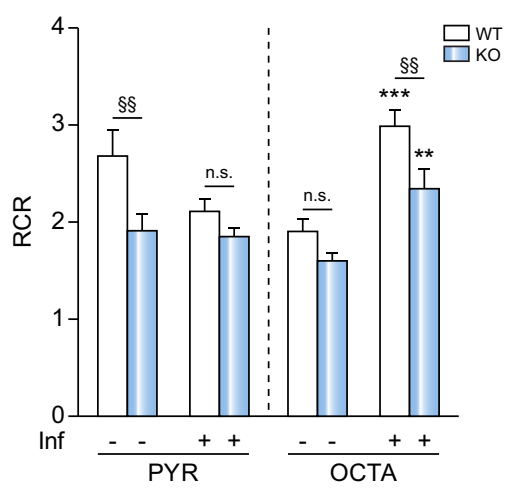

Fig. 2. Whole body Ppara-deficiency modulates hepatic metabolic and inflammatory transcriptional responses to infection. Livers from Ppara WT and KO mice injected (ip) with vehicle (PBS) (Control) or E. coli $\left(4 \times 10^{8}\right.$ live bacteria) (Infected) were collected after $16 \mathrm{~h}$ and transcriptomic analysis was performed ( $\mathrm{n}=6$ mice/group). (A) Top enriched GO terms for genes differentially expressed comparing infection $v$ s. control in Ppara WT mice. (B) Hierarchical clustering and (C) dot plot of genes affected by infection in Ppara WT or KO mice. (D) Selected genes from the "fatty acid oxidation pathway" GO term of Cluster 2. (E) Mitochondrial respiration measured with (PYR or OCTA as described in methods ( $\mathrm{n}=7-8$ mice/group). Statistical differences are indicated (2-way ANOVA: ${ }^{* * *} p<0.001,{ }^{* *} p<0.01$ and ${ }^{*} p<0.05$ for effect of infection; $\S{ } p<0.001 ; \S \S p<0.01 ;{ }^{\S} p<0.05$ for genotype effect; n.s.: non-significant). GO, Gene Ontology; KO, knockout; PYR, pyruvate/malate; OCTA, octanoylcarnitine/malate; WT, wild-type.

metabolism (e.g. Cd36, Acox1, Vlcad and Lcad, Fig. 4B), as well as Ppara itself (Fig. 4C). Interestingly, the induction of hepatic Atgl and Cpt1a expression upon sepsis was independent of hepato- cyte PPAR $\alpha$ (Fig. 4B). Conversely, hepatic Hmgcs2 expression was virtually undetectable upon sepsis in Ppara ${ }^{\text {hepKo }}$ mice (Fig. 4B). Bacterial infection increased Atgl, but not Hmgcs2 or 
A
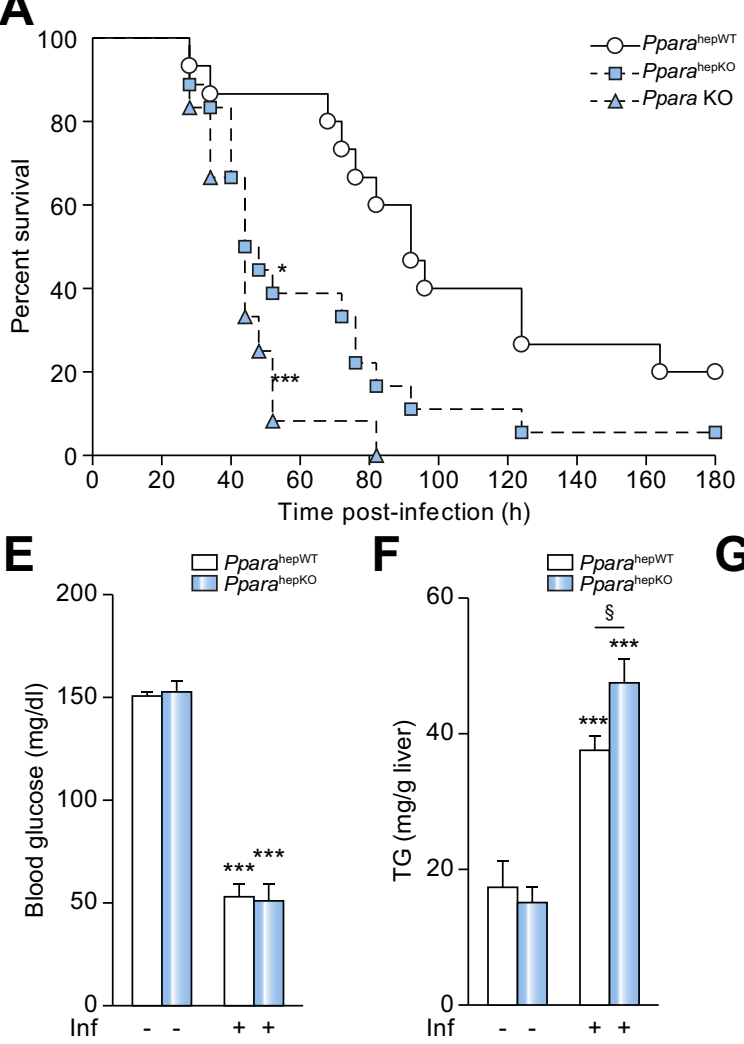

B

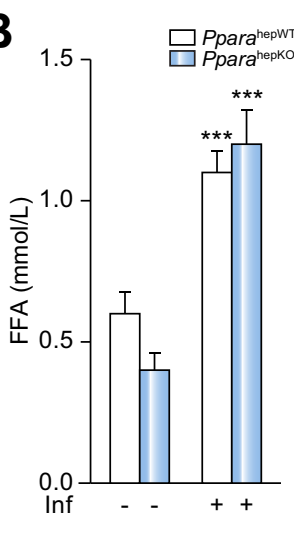

G

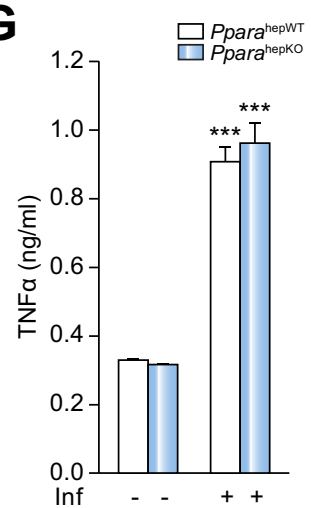

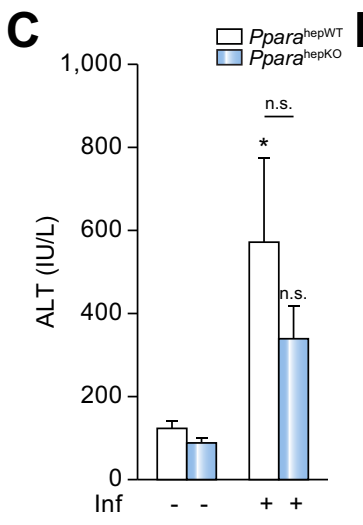
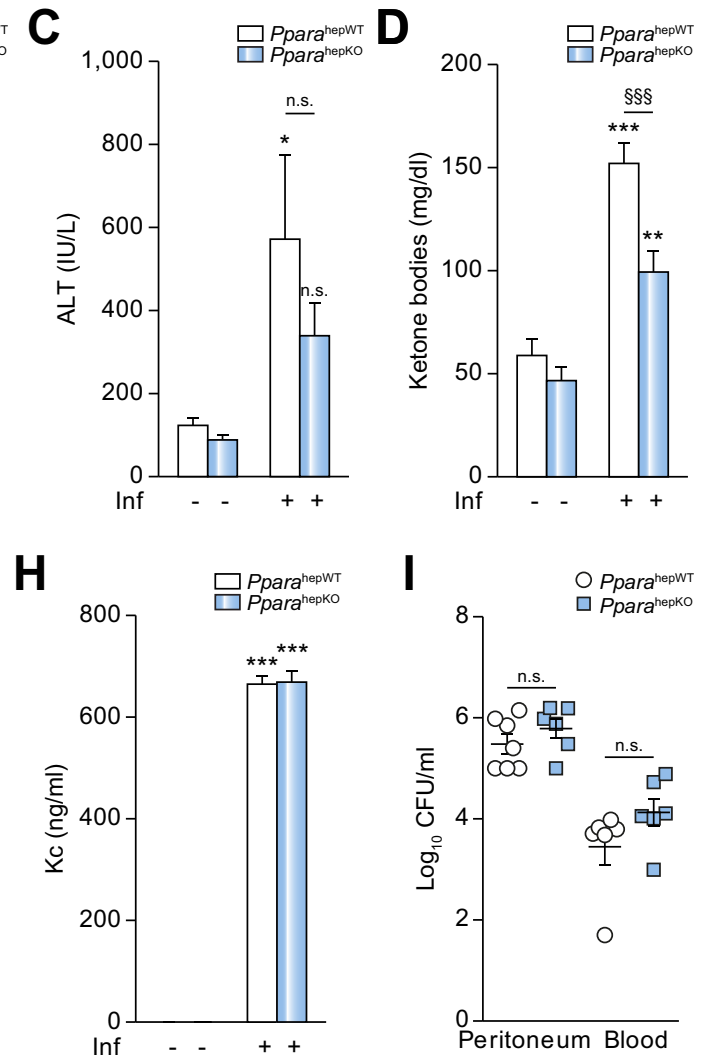

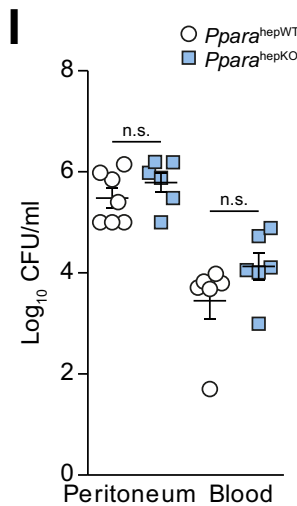

Fig. 3. Hepatocyte-specific Ppara-deficiency results in metabolic perturbations and aggravates mortality during bacterial infection. (A) Ppara ${ }^{\text {hepWT }}$, Ppara $^{\text {hepKO }}$, and Ppara KO mice were injected (ip) with E. coli $\left(7 \times 10^{8}\right.$ live bacteria). Survival was followed for 8 days after bacterial infection ( $\mathrm{n}=12-18$ mice/group). Plasma was collected (G, H) 5 h or (B-E) 16 h after bacterial infection and (B) FFAs, (C) ALT, (D) ketone bodies, (E) blood glucose, (G) TNF $\alpha$ and (H) $\mathrm{Kc} / \mathrm{Cxcl} 1$ concentrations were measured as described in methods. Livers, peritoneal fluid and blood were collected $16 \mathrm{~h}$ after injection and (F) TG content and (I) bacterial levels were determined as described in methods ( $\mathrm{n}=7-8$ mice/group). Statistical differences are indicated (Survival test: Log-rank (Mantel-Cox) Test. ${ }^{*} p<0.05,{ }^{* * *} p<0.001$ compare to survival of PparahepWT; 2 -way ANOVA: ${ }^{\S \S} p<0.001$; ${ }^{\S} p<0.01$; ${ }^{\S} p<0.05$ for genotype effect; n.s.: non-significant). ALT, alanine aminotransferase; FFAs, free fatty acids; KO, knockout; TG, triglycerides; WT, wild-type.
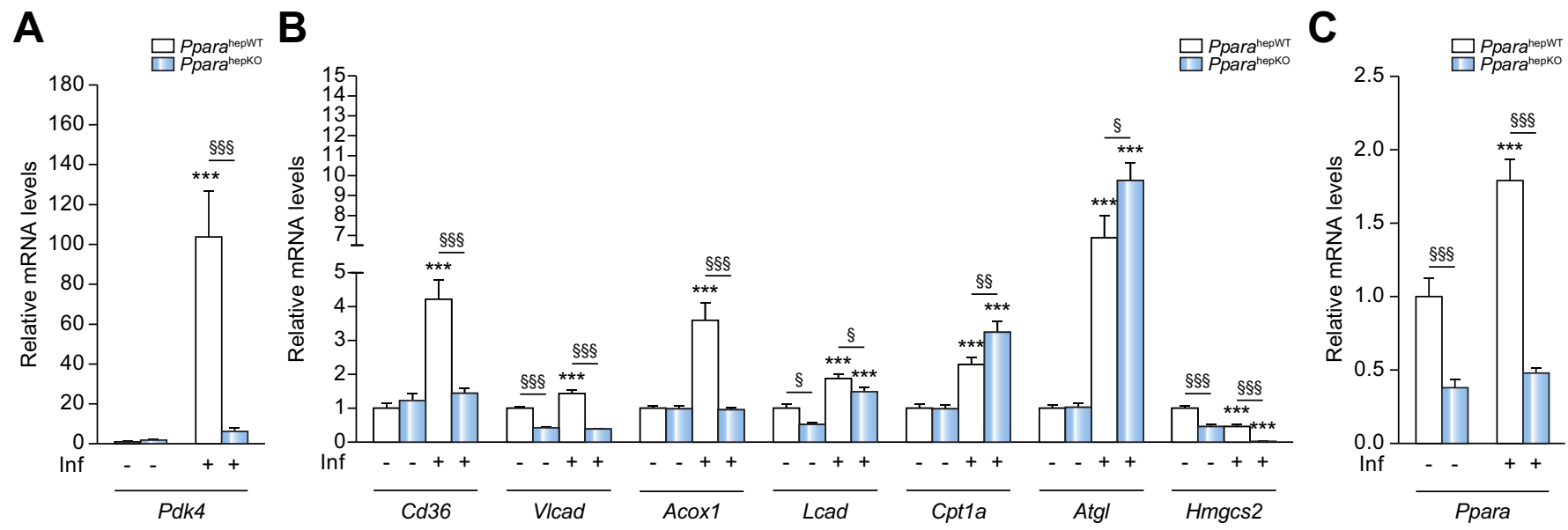

Fig. 4. Hepatocyte-specific Ppara-deficiency impairs the response of lipid metabolism genes to bacterial infection. Ppara ${ }^{\text {hepWT }}$, Pраra ${ }^{\text {hepKO }}$ mice $^{\text {were }}$ injected (ip) with vehicle (PBS) (-) or with E. coli $\left(6 \times 10^{8}\right.$ live bacteria) (inf) (+). Livers were collected $16 \mathrm{~h}$ after infection and hepatic mRNA expression of (A) Pdk4, (B) genes involved in lipid metabolism and (C) Ppara was measured. Statistical differences are indicated $\left(2\right.$-way ANOVA: ${ }^{* * *} p<0.001$, ${ }^{* *} p<0.01$ and ${ }^{*} p<0.05$ for effect of infection; ${ }^{\S \S} p<0.001 ;{ }^{\S} p<0.01$; ${ }^{\S} p<0.05$ for effect of genotype; n.s.: non-significant).

Dgat1 expression at the protein level (Fig. S8). Moreover, Hmgcs2 protein levels were lower in Ppara ${ }^{\text {hepKo }}$ mice both in uninfected and infected conditions. Whereas Atgl protein induction appeared less pronounced upon sepsis in Ppara ${ }^{\text {hepKO }}$ mice,
Dgat1 protein expression only increased in Ppara ${ }^{\text {hepKO }}$ mice, both consistent with increased hepatic TG content. Together, these data indicate that hepatocyte-specific PPAR $\alpha$-deficiency profoundly affects the hepatic metabolic response to infection. 
Ppara-deficiency regulates the inflammatory response, but does not promote innate immune cell recruitment or inhibit autophagy in the liver upon bacterial sepsis

To determine the contribution of non-hematopoietic PPAR $\alpha$ to systemic inflammation in sepsis, expression of inflammatory genes was measured in livers and spleens from whole body Ppara KO, chimeric Ppara WTbm->KO mice and their respective controls. The induction of Tnfa, Mcp1, Il6 and Ifng upon sepsis was markedly attenuated in livers (Fig. 5A), and, to a lesser extent, in spleens (Fig. S9) of whole body Ppara KO mice compared to controls. Likewise, induction of the vascular inflammation markers Vcam1 and Icam1 (Fig. 5B) and the mitochondrial anti-oxidant enzyme Sod2 (Fig. 5C) was lower in livers of whole body Ppara KO mice than in their WT counterparts. By contrast, the hepatic and vascular inflammatory and anti-oxidant responses (Fig. 5D,E), as well as MPO activity (Fig. 5F) and immune cell recruitment (Fig. S10) were similar in chimeric Ppara WTbm->KO and WTbm->WT mice, despite differing survival outcomes (Fig. $1 \mathrm{~A}$ and Fig. S1A). Interestingly, in Ppara $^{\text {hepKO }}$ mice, the induction of inflammatory genes (Fig. 6A) upon sepsis was either higher (Tnfa) or unchanged (Mcp1, Il6), whereas neutrophil and monocyte/macrophage recruitment was again similar (Ly6G and Moma2 stainings, Fig. 6C-E) upon infection. Altogether, these data indicate that the attenuated inflammatory response observed in livers of whole body Ppara
KO mice depends on hematopoietic, but not hepatic Ppara expression.

Because autophagy may play a protective role during sep$\operatorname{sis}^{28}$ and PPAR $\alpha$ mediates fasting-induced autophagy, ${ }^{29}$ markers of autophagy were assessed in whole body and hepatocytespecific Ppara-deficient mice. Whereas sepsis increased expression of certain autophagy genes, their regulation was not different in whole body Ppara KO mice (Fig. S11A). Moreover, hepatocyte-specific Ppara-deficiency (Fig. S11B-C) resulted in more pronounced induction of Ulk1, Atg5, Bnip3 and Becn1 gene expression and Lc3b-II/I protein ratio, suggestive of a compensatory induction of autophagy to combat the deleterious response to sepsis in Ppara ${ }^{\text {hepKO }}$ mice. Altogether, these data indicate that hepatocyte PPAR $\alpha$ expression contributes to protection against sepsis by controlling the systemic metabolic response.

\section{$P P A R \propto$ expression and activity is lower in livers of critically ill patients}

To determine whether hepatic PPAR $\alpha$ expression is altered in critically ill humans, livers from non-surviving critically ill patients and healthy controls were analyzed for PPARA and its targets gene expression (Fig. 7A). Interestingly, PPARA expression was lower in livers of critically ill patients. Moreover, expression of genes involved in TG lipolysis (ATGL), glucose oxidation (PDK4),
A
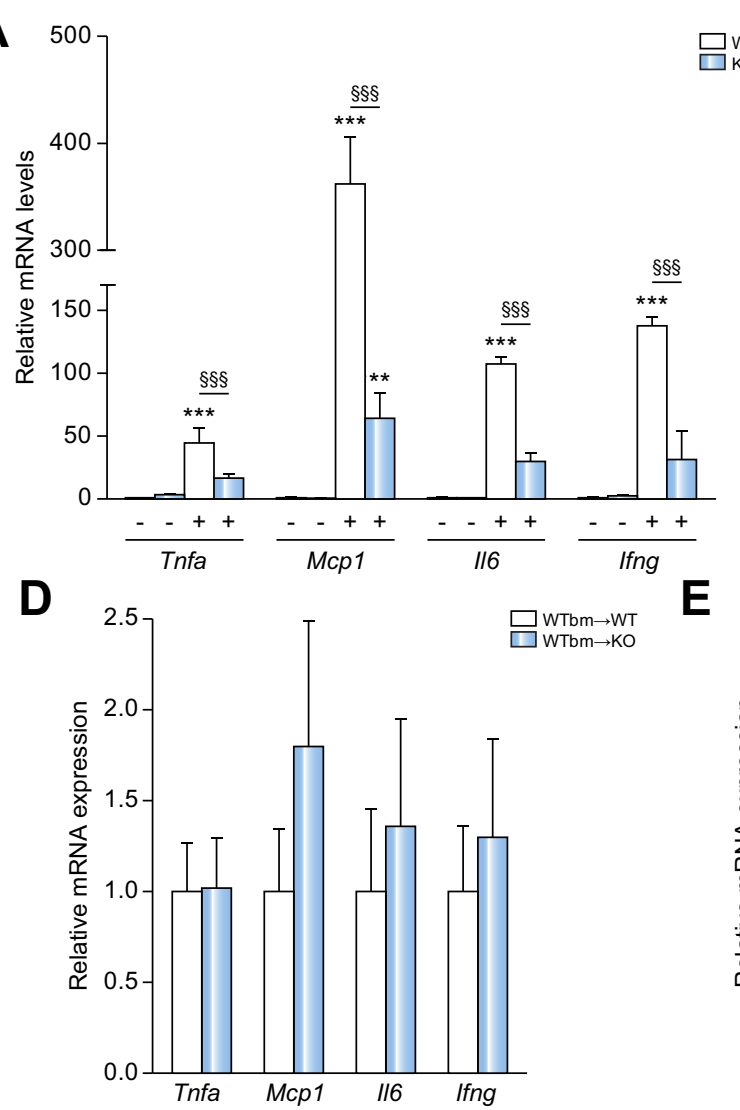

B

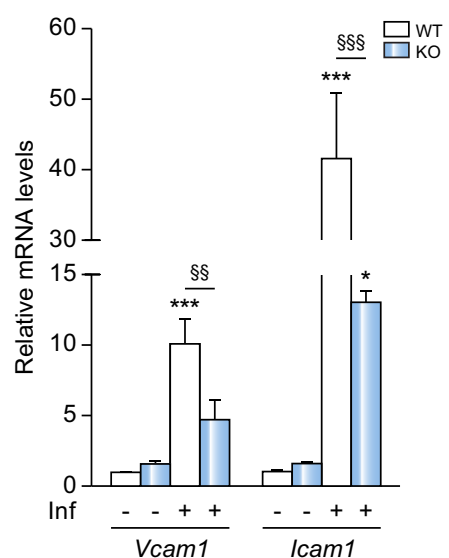

C

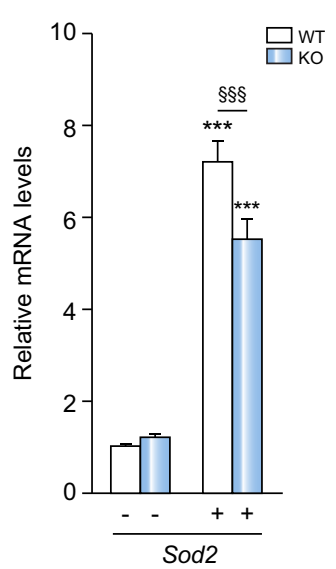

E

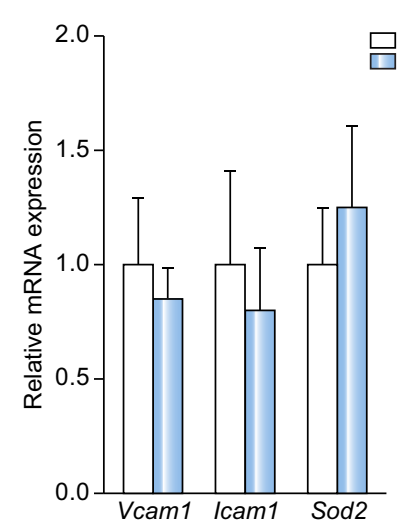

$\mathbf{F}$

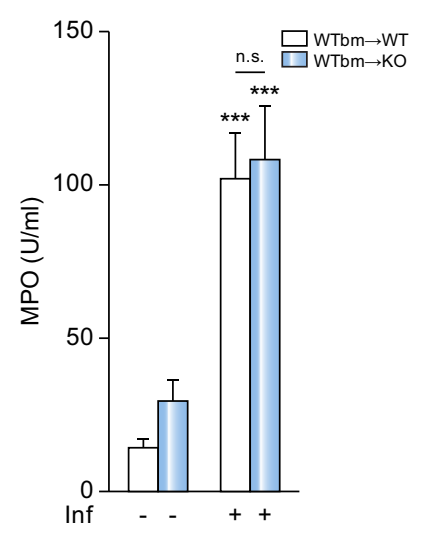

Fig. 5. The sepsis-induced inflammatory response occurs through hematopoietic PPAR $\boldsymbol{\alpha}$. (A-C) Whole body Ppara WT and KO mice or (D-F) chimeric Ppara WTbm->WT and WTbm->KO mice were injected (ip) with vehicle (PBS) $(-)$ or E. coli $\left(4 \times 10^{8}\right.$ live bacteria) (Inf) (+). Livers were collected $16 \mathrm{~h}$ after infection and mRNA expression of genes involved in (A, D) inflammation, (B, E) endothelial activation, and (C,E) oxidative stress, were analyzed using RT-qPCR. (F) Plasma MPO activity was measured as described in methods ( $\mathrm{n}=8$ mice/group). Statistical differences are indicated (2-way ANOVA: ${ }^{* * *} p<0.001$, ${ }^{* *} p<0.01$ and ${ }^{*} p<0.05$ for effect of infection; ${ }^{\S \S} p<0.001$; ${ }^{\S \S} p<0.01$; ${ }^{\S} p<0.05$ for genotype effect; ns: non-significant). KO, knockout; MPO, myeloperoxidase; RT-qPCR, quantitative reverse transcription PCR; WT, wild-type. 
A

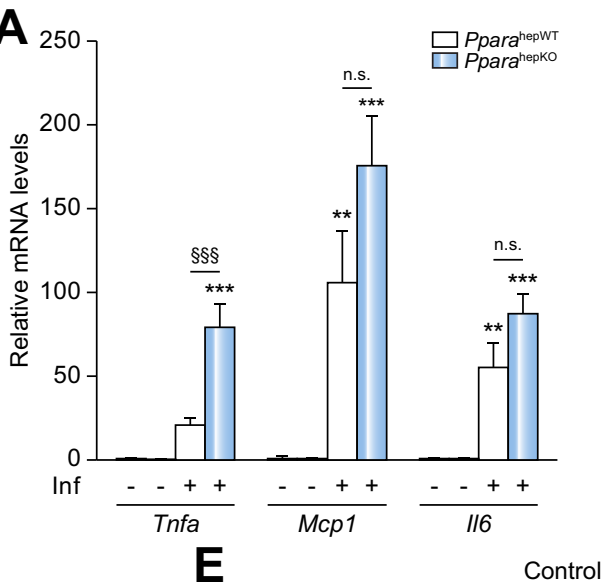

B

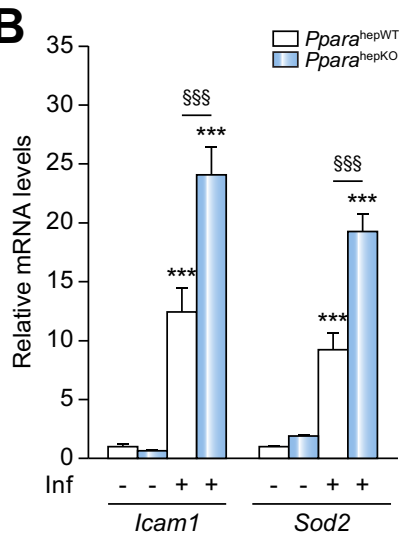

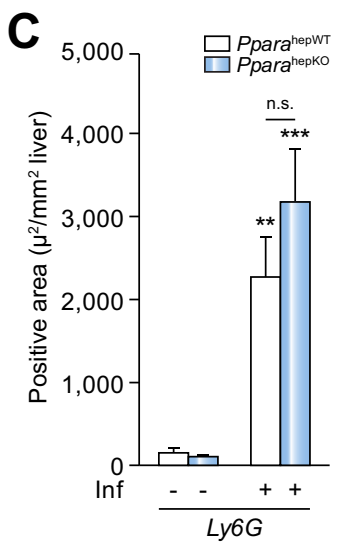

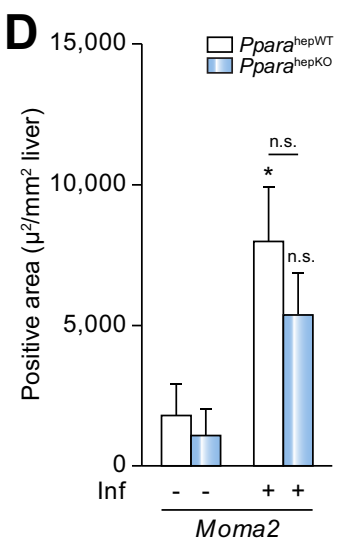

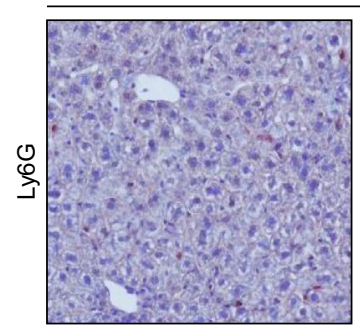
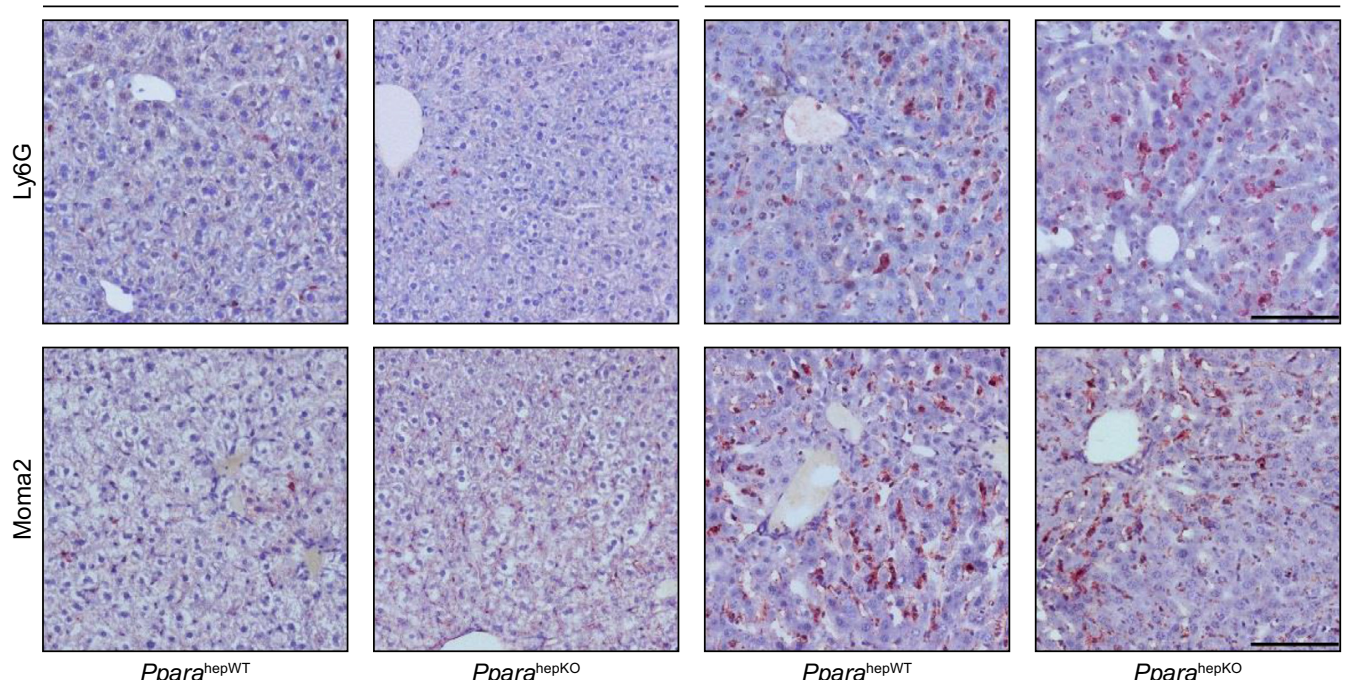

Fig. 6. Hepatocyte-specific Ppara-deficiency modulates the inflammatory response in the liver without affecting innate immune cell recruitment upon bacterial infection. Ppara hepWT ${ }^{\text {Ppara }}{ }^{\text {hepO }}$ mice were injected (ip) with vehicle (PBS) (-) or E. coli (6x10 $0^{8}$ live bacteria) (inf) $(+)$. Livers were collected 16 h after infection and mRNA expression of genes involved in (A) inflammation, (B) endothelial activation and oxidative stress were analyzed using RT-qPCR. Liver sections stained for Ly6G (E, top panel) and Moma2 (E, bottom panel) and quantified (C, D), respectively, using NIS Element software ( $\mathrm{n}=7-8$ mice/group) $($ Bar $=100 \mu \mathrm{m})$. Statistical differences are indicated $\left(2\right.$-way ANOVA: ${ }^{* * *} p<0.001,{ }^{* *} p<0.01$ and ${ }^{*} p<0.05$ for effect of infection; ${ }^{\S \S} p<0.001 ;{ }^{\S \S} p<0.01$; ${ }^{\S} p<0.05$ for genotype effect; n.s.: non-significant). KO, knockout; RT-qPCR, quantitative reverse transcription PCR; WT, wild-type.

FA uptake and $\beta$-oxidation $(C D 36, L C A D)$ and ketogenesis (HMGCS2) were also lower and correlated with PPARA expression (Fig. 7A,B). Surprisingly, PPARA mRNA levels did not correlate with serum cytokine levels in these patients (Fig. 7B), suggesting a critical role for hepatic PPAR $\alpha$ in the metabolic, but not in the inflammatory response to sepsis in critically ill human patients.

\section{Discussion}

Our results demonstrate that PPAR $\alpha$ protects against sepsis primarily by controlling the metabolic response in hepatocytes, by shifting its energy utilization from glucose to FAs and increasing ketogenesis.

The host defense toward bacterial infection is a complex response involving resistance (to limit microbial burden) and tolerance (to limit tissue injury and organ dysfunction) mechanisms. These processes require metabolic reprogramming in immune and non-immune cells. ${ }^{30}$ Resistance is characterized by a balance between local activation of pro-inflammatory pathways to restrain and eliminate invading pathogens and anti-inflammatory pathways required to prevent exaggerated systemic inflammation. ${ }^{31,32}$ Our data show that whole body Ppara-deficiency attenuates organ and systemic inflammatory responses upon infection. This contrasts with previous observations in models of sterile chronic and acute inflammation in which Ppara-deficiency results in exacerbated inflammatory responses to endotoxemia in vascular, splenic and liver cells. ${ }^{33}$ Accordingly, whole body Ppara-deficiency also resulted in a decreased pro-inflammatory response and survival in a cecal ligation sepsis model. ${ }^{15}$

Interestingly, our data and that of others indicate that nonhematopoietic PPAR $\alpha$ action is an important determinant of survival. Studies by Standage et al. suggest that heart PPAR $\alpha$ expression contributes to survival during sepsis by increasing cardiac performance and FA oxidation. ${ }^{16,17}$ In the present study, we demonstrate that PPAR $\alpha$ expression and activation in hepatocytes, but not immune cells, contributes to protection against sepsis by promoting an appropriate metabolic response, hence improving survival. Sepsis activates hepatic PPAR $\alpha$, which results in activation of FA metabolism and ketogenesis-related target genes, elevating the level of ketone bodies in the plasma. Indeed, Ppara ${ }^{\text {hepKO }}$ mice displayed higher hepatic TG accumula- 
A

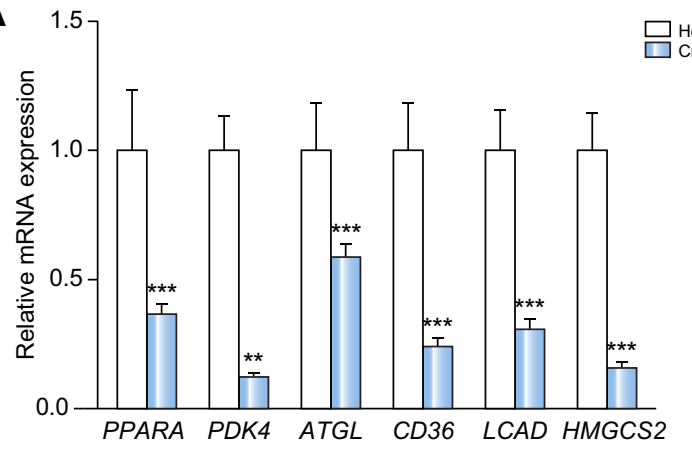

B

\begin{tabular}{llc}
\multicolumn{3}{c}{ Correlation of PPARa mRNA with } \\
\hline Metabolic genes & $\mathrm{r}$ & $p$ value \\
\hline PDK4 & 0.4004 & ${ }^{* *} p=0.0053$ \\
ATGL & 0.7414 & ${ }^{* * *} p<0.001$ \\
CD36 & 0.4096 & ${ }^{* *} p=0.0042$ \\
LCAD & 0.6043 & ${ }^{* * *} p<0.001$ \\
HMGCS2 & 0.5646 & ${ }^{* *} p<0.001$ \\
\hline Serum levels & & \\
\hline TNF $\alpha$ & 0.236 & $p=0.2$ \\
MCP1 & 0.009 & $p=0.9$ \\
IL-6 & 0.053 & $p=0.8$ \\
IFNY & 0.068 & $p=0.7$ \\
IL-10 & 0.139 & $p=0.4$ \\
\hline
\end{tabular}

Fig. 7. PPARA gene expression in liver biopsies of critically ill patients correlates with decreased expression of fatty acid utilization genes. (A) Liver biopsies from elective surgery $(n=20)$ and critically ill patients $(n=46)$ were collected and mRNA was analyzed using RT-qPCR. Statistical differences are indicated (Wilcoxon test: ${ }^{* * *} p<0.001$; ${ }^{* *} p<0.01$; compared to healthy). Serum cytokines were quantified as described in methods. (B) Correlations of hepatic PPARA mRNA expression with metabolic gene expression or serum cytokine levels from critically ill patients were calculated. Statistical differences are indicated (Pearson $\left.(\mathrm{r}):{ }^{* * *} p<0.001 ;{ }^{* *} p<0.01\right)$. RT-qPCR, quantitative reverse transcription PCR.

tion, reduced plasma ketonemia, and lower hepatic expression of FA metabolism and ketogenesis genes. Decreased ketogenesis in septic Ppara-deficient mice was unlikely due to defective AT lipolysis, since plasma FFA levels were unaffected by whole body and hepatocyte-specific Ppara-deficiency.

Defective FA oxidation and ketogenesis in septic Pparadeficient mice may indirectly contribute to the aggravation of hypoglycemia and mortality. Mouse models displaying FA oxidation defects are often hypoglycemic upon lipopolysaccharide administration, e.g. Mcad-deficient mice ${ }^{34,35}$ and Tbp2-deficient mice. ${ }^{36}$ Moreover, several lines of evidence indicate that PPAR $\alpha$ plays an important role in glucose homeostasis. ${ }^{37}$ Under septic conditions, the hypoglycemia in whole body Ppara-deficient mice may involve increased hepatic glucose utilization. Indeed, Ppara-deficiency impairs the induction of Pdk4 gene expression upon sepsis, whereas the expression of gluconeogenic genes was not affected. Still, assessment of mitochondrial respiration in Ppara-deficient livers suggests that infection does not increase pyruvate oxidation. Thus, the hypoglycemia might also result from increased peripheral glucose uptake by metabolic organs, such as the heart, muscle and brain, to compensate for both the inability to catabolize $\mathrm{FA}^{38,39}$ and reduced ketone body availability. In line, septic Ppara ${ }^{\text {hepKO }}$ mice display less pronounced hypoglycemia than whole body Ppara deficient mice. However, it has been shown that decreased FA oxidation and ketogenesis as a result of Ppara or Fgf21-deficiency can lead to an inability to maintain tissue tolerance to bacterial sepsis leading to neuronal dysfunction and death. ${ }^{40}$ Moreover, ketone body therapy protects against lipotoxicity and acute liver failure in Ppara-deficient mice. ${ }^{41}$ Together with our data, these data suggest that the increased mortality during sepsis may be caused by a deficiency in beneficial energetic substrates produced by FA oxidation in hepatocytes, such as ketone bodies, to maintain tissue protection.

Interestingly, in livers of non-surviving critically ill patients, PPARA MRNA levels are lower and correlate with the lower expression of genes involved in lipid and glucose metabolism, but not with plasma markers of inflammation. These data corroborate findings from a clinical metabolomic study showing that lactate, pyruvate, acetyl-carnitine and several citric acid cycle metabolites were higher in sepsis non-survivors compared to survivors, suggesting that a profound defect in FA $\beta$ oxidation, possibly as a result of mitochondrial dysfunction, is associated with the incidence of death in critical ill patients. ${ }^{42,43}$

In conclusion, we have shown that during sepsis Pparadeficiency in hepatocytes is deleterious, as it impairs the adaptive metabolic shift from glucose to FA utilization. While most current approaches to treat sepsis aim to harness the inflammatory response, our results might pave the way for strategies based on adaptive energy homeostasis.

\section{Financial support}

This work was supported by grants from European Genomic Institute for Diabetes (EGID, ANR-10-LABX-46), the Conseil régional Nord Pas-de-Calais and the Fonds européens de développement régional (FEDER). J. Haas was supported by the European Molecular Biology Organization (EMBO) LongTerm Fellowship (ALTF2014-277), Y. Deleye by a doctoral fellowship from the Nouvelle Société Française d'Athérosclérose, K. Wouters by European FP7 Postdoctoral fellowship (PIEF-GA2009-235221), EFSD/GlaxoSmithKline Research and European Atherosclerosis Society grants. D. Mesotten is a senior clinical investigator for the Research Foundation - Flanders. G. Van den Berghe receives research financing through the Methusalem program (Flemish government) and holds an "ERC Advanced Grant". W. Wahli was supported by the Lee Kong Chian School of Medicine, Nanyang Technological University Singapore Start-Up Grant and holds a Chaire d'Excellence Pierre de Fermat (Toulouse). H. Guillou is supported by grants from Région Occitanie and ANR "Hepatokind". B. Staels holds an "ERC advanced Grant” (694717).

\section{Conflict of interest}

The authors declare no conflicts of interest that pertain to this work.

Please refer to the accompanying ICMJE disclosure forms for further details.

\section{Authors' contributions}

Contribution to conception and design, technical support: RP, JH, NH, EB, YD, JV, CC, SAH, VL, SL, SM, PG, EV, EB, BD, HD, CG, SF, FL, AT, AM, WW, BS. Data acquisition, data analysis and interpretation: RP, JH, NH, EB, YD, DM, LL, JV, KW, SM, PG, HG, DD, BS. Drafting of the manuscript, statistical analysis: RP, JH, 
NH, EB, YD, DM, LL, KW, HG, BS. Critical revision of the manuscript for intellectual content: RP, JH, DM, AT, WW, GVdB, HG, DD, BS.

\section{Acknowledgments}

We thank A. Lecluse, C. Paquet, A. Lucas, C. Rommens (Inserm U1011) for technical assistance.

\section{Supplementary data}

Supplementary data to this article can be found online at https://doi.org/10.1016/j.jhep.2018.12.037.

\section{References}

Author names in bold designate shared co-first authorship

[1] Angus DC, van der Poll T. Severe sepsis and septic shock. N Engl J Med 2013;369:840-851. https://doi.org/10.1056/NEJMra1208623.

[2] Venkatesh B, Finfer S, Cohen J, Rajbhandari D, Arabi Y, Bellomo R, et al. Adjunctive glucocorticoid therapy in patients with septic shock. N Engl J Med 2018;378:797-808. https://doi.org/10.1056/NEJMoa1705835.

[3] van den Berghe G, Wouters P, Weekers F, Verwaest C, Bruyninckx F, Schetz $\mathrm{M}$, et al. Intensive insulin therapy in critically ill patients. N Engl J Med 2001;345:1359-1367. https://doi.org/10.1056/NEJMoa011300.

[4] Casaer MP, Mesotten D, Hermans G, Wouters PJ, Schetz M, Meyfroidt G, et al. Early versus late parenteral nutrition in critically ill adults. N Engl J Med 2011;365:506-517. https://doi.org/10.1056/NEJMoa1102662.

[5] Liu TF, Brown CM, El Gazzar M, McPhail L, Millet P, Rao A, et al. Fueling the flame: bioenergy couples metabolism and inflammation. J Leukoc Biol 2012;92:499-507. https://doi.org/10.1189/jlb.0212078.

[6] Lang CH, Dobrescu C. Gram-negative infection increases noninsulinmediated glucose disposal. Endocrinology 1991;128:645-653. https:// doi.org/10.1210/endo-128-2-645.

[7] Stoner HB. Interpretation of the metabolic effects of trauma and sepsis. J Clin Pathol 1987;40:1108-1117.

[8] Cree MG, Aarsland A, Herndon DN, Wolfe RR. Role of fat metabolism in burn trauma-induced skeletal muscle insulin resistance. Crit Care Med 2007;35:S476-S483.

https://doi.org/10.1097/01. CCM.0000278066.05354.53.

[9] Singer M, De Santis V, Vitale D, Jeffcoate W. Multiorgan failure is an adaptive, endocrine-mediated, metabolic response to overwhelming systemic inflammation. Lancet 2004;364:545-548. https://doi.org/ 10.1016/S0140-6736(04)16815-3.

[10] Dubois V, Eeckhoute J, Lefebvre P, Staels B. Distinct but complementary contributions of PPAR isotypes to energy homeostasis. J Clin Invest 2017;127:1202-1214. https://doi.org/10.1172/JCI88894.

[11] Marx N, Duez H, Fruchart JC, Staels B. Peroxisome proliferator-activated receptors and atherogenesis: regulators of gene expression in vascular cells. Circ Res 2004;94:1168-1178.

[12] Leone TC, Weinheimer CJ, Kelly DP. A critical role for the peroxisome proliferator-activated receptor alpha (PPARalpha) in the cellular fasting response: the PPARalpha-null mouse as a model of fatty acid oxidation disorders. PNAS 1999;96:7473-7478.

[13] Kersten S, Seydoux J, Peters JM, Gonzalez FJ, Desvergne B, Wahli W. Peroxisome proliferator-activated receptor alpha mediates the adaptive response to fasting. J Clin Investig 1999;103:1489-1498.

[14] Devchand PR, Keller H, Peters JM, Vazquez M, Gonzalez FJ, Wahli W. The PPARalpha-leukotriene B4 pathway to inflammation control. Nature 1996;384:39-43.

[15] Standage SW, Caldwell CC, Zingarelli B, Wong HR. Reduced peroxisome proliferator-activated receptor $\alpha$ expression is associated with decreased survival and increased tissue bacterial load in sepsis. Shock 2012;37:164-169. https://doi.org/10.1097/SHK.0b013e31823f1a00.

[16] Standage SW, Waworuntu RL, Delaney MA, Maskal SM, Bennion BG, Duffield JS, et al. Nonhematopoietic peroxisome proliferator-activated receptor- $\alpha$ protects against cardiac injury and enhances survival in experimental polymicrobial sepsis. Crit Care Med 2016;44:e594-e603. https://doi.org/10.1097/CCM.0000000000001585.

[17] Standage SW, Bennion BG, Knowles TO, Ledee DR, Portman MA, McGuire $\mathrm{JK}$, et al. PPAR $\alpha$ augments heart function and cardiac fatty acid oxidation in early experimental polymicrobial sepsis. Am J Physiol Heart Circ
Physiol

2017:312:H239-H249.

$\underline{\text { https://doi.org/10.1152/ }}$ aipheart.00457.2016.

[18] Lee SS, Pineau T, Drago J, Lee EJ, Owens JW, Kroetz DL, et al. Targeted disruption of the alpha isoform of the peroxisome proliferator-activated receptor gene in mice results in abolishment of the pleiotropic effects of peroxisome proliferators. Mol Cell Biol 1995; 15:3012-3022.

[19] Montagner A, Polizzi A, Fouché E, Ducheix S, Lippi Y, Lasserre F, et al. Liver PPAR $\alpha$ is crucial for whole-body fatty acid homeostasis and is protective against NAFLD. Gut 2016;65:1202-1214. https://doi.org/ 10.1136/gutjinl-2015-310798.

[20] Bradley PP, Christensen RD, Rothstein G. Cellular and extracellular myeloperoxidase in pyogenic inflammation. Blood 1982;60:618-622.

[21] Langouche L, Vanhorebeek I, Vlasselaers D, Vander Perre S, Wouters PJ, Skogstrand K, et al. Intensive insulin therapy protects the endothelium of critically ill patients. J Clin Invest 2005;115:2277-2286. https://doi.org/ $10.1172 / \mathrm{ICI} 25385$.

[22] Carvalho BS, Irizarry RA. A framework for oligonucleotide microarray preprocessing. Bioinformatics 2010;26:2363-2367. https://doi.org/ 10.1093/bioinformatics/btq431.

[23] Phipson B, Lee S, Majewski IJ, Alexander WS, Smyth GK. Robust hyperparameter estimation protects against hypervariable genes and improves power to detect differential expression. Ann Appl Stat 2016;10:946-963. https://doi.org/10.1214/16-AOAS920.

[24] van der Laan MJ, Dudoit S, Pollard KS. Multiple testing. Part II. Step-down procedures for control of the family-wise error rate. Stat Appl Genet Mol Biol 2004;3:Article14. https://doi.org/10.2202/1544-6115.1041.

[25] Alexa A, Rahnenführer J, Lengauer T. Improved scoring of functional groups from gene expression data by decorrelating GO graph structure. Bioinformatics 2006;22:1600-1607. https://doi.org/10.1093/bioinformatics/btl140.

[26] Yu G, Wang L-G, Han Y, He Q-Y. clusterProfiler: an R package for comparing biological themes among gene clusters. OMICS 2012;16:284-287. https://doi.org/10.1089/omi.2011.0118.

[27] Lalloyer F, Wouters K, Baron M, Caron S, Vallez E, Vanhoutte J, et al. Peroxisome proliferator-activated receptor-alpha gene level differently affects lipid metabolism and inflammation in apolipoprotein E2 knock-in mice. Arterioscler Thromb Vasc Biol 2011;31:1573-1579. https://doi. org/10.1161/ATVBAHA.110.220525.

[28] Takahashi W, Watanabe E, Fujimura L, Watanabe-Takano H, Yoshidome $\mathrm{H}$, Swanson PE, et al. Kinetics and protective role of autophagy in a mouse cecal ligation and puncture-induced sepsis. Crit Care 2013;17: R160. https://doi.org/10.1186/cc12839.

[29] Lee JM, Wagner M, Xiao R, Kim KH, Feng D, Lazar MA, et al. Nutrientsensing nuclear receptors coordinate autophagy. Nature 2014;516:112-115. https://doi.org/10.1038/nature13961.

[30] Gómez H, Kellum JA, Ronco C. Metabolic reprogramming and tolerance during sepsis-induced AKI. Nat Rev Nephrol 2017;13:143-151. https:/ doi.org/10.1038/nrneph.2016.186.

[31] Aziz M, Jacob A, Yang W-L, Matsuda A, Wang P. Current trends in inflammatory and immunomodulatory mediators in sepsis. J Leukoc Biol 2013;93:329-342. https://doi.org/10.1189/jlb.0912437.

[32] Bosmann M, Ward PA. The inflammatory response in sepsis. Trends Immunol 2013;34:129-136. https://doi.org/10.1016/i.it.2012.09.004.

[33] Delerive P, Fruchart JC, Staels B. Peroxisome proliferator-activated receptors in inflammation control. J Endocrinol 2001;169:453-459.

[34] Herrema H, Derks TGJ, van Dijk TH, Bloks VW, Gerding A, Havinga R, et al. Disturbed hepatic carbohydrate management during high metabolic demand in medium-chain acyl-CoA dehydrogenase (MCAD)-deficient mice. Hepatology 2008;47:1894-1904. https://doi.org/10.1002/ hep. 22284.

[35] Spiekerkoetter U, Wood PA. Mitochondrial fatty acid oxidation disorders: pathophysiological studies in mouse models. J Inherit Metab Dis 2010;33:539-546. https://doi.org/10.1007/s10545-010-9121-7.

[36] Oka S, Liu W, Yoshihara E, Ahsan MK, Ramos DAL, Son A, et al. Thioredoxin binding protein-2 mediates metabolic adaptation in response to lipopolysaccharide in vivo. Crit Care Med 2010;38:2345-2351. https://doi.org/10.1097/CCM.0b013e3181f85b2a.

[37] Peeters A, Baes M. Role of PPARalpha in hepatic carbohydrate metabolism. PPAR Res 2010.

[38] Romanosky AJ, Bagby GJ, Bockman EL, Spitzer JJ. Increased muscle glucose uptake and lactate release after endotoxin administration. Am J Physiol 1980;239:E311-E316. https://doi.org/10.1152/ajpendo.1980.239.5.E311.

[39] Knauf C, Rieusset J, Foretz M, Cani PD, Uldry M, Hosokawa M, et al. Peroxisome proliferator-activated receptor-alpha-null mice have increased white adipose tissue glucose utilization, GLUT4, and fat mass: 


\section{JOURNAL}

OF HEPATOLOGY

Role in liver and brain. Endocrinology 2006;147:4067-4078. https://doi. org/10.1210/en.2005-1536.

[40] Wang A, Huen SC, Luan HH, Yu S, Zhang C, Gallezot J-D, et al. Opposing effects of fasting metabolism on tissue tolerance in bacterial and viral inflammation 1512-1525.e12. Cell 2016;166. https://doi.org/10.1016/ j.cell.2016.07.026.

[41] Pawlak M, Baugé E, Lalloyer F, Lefebvre P, Staels B. Ketone body therapy protects from lipotoxicity and acute liver failure upon Ppar $\alpha$ deficiency. Mol Endocrinol 2015;29:1134-1143. https://doi.org/10.1210/me.2014$\underline{1383}$.
[42] Langley RJ, Tsalik EL, van Velkinburgh JC, Glickman SW, Rice BJ, Wang $\mathrm{C}$, et al. An integrated clinico-metabolomic model improves prediction of death in sepsis. Sci Transl Med 2013;5:195ra95. https://doi.org/10.1126/ scitranslmed.3005893.

[43] Langley RJ, Tipper JL, Bruse S, Baron RM, Tsalik EL, Huntley J, et al. Integrative "omic" analysis of experimental bacteremia identifies a metabolic signature that distinguishes human sepsis from systemic inflammatory response syndromes. Am J Respir Crit Care Med 2014;190:445-455. https://doi.org/10.1164/rccm.201404-06240C. 